\title{
Cooperação e Conflito na Relação Movimentos Sociais e Estado
}

Euzeneia Carlos'

\section{Resumo}

O artigo analisa a reconfiguração das relações entre movimentos sociais e Estado no contexto brasileiro pós anos noventa, e os efeitos institucionais na ação coletiva. As interações socioestatais são examinadas através do método comparativo, aplicado a quatro organizações de movimentos sociais da região metropolitana do Espírito Santo, ao longo de três décadas ( 1980 a 2010), mediante instrumentos metodológicos qualitativos e quantitativos. São eles: Federação das Associações de Moradores da Serra (Fams), Conselho Popular de Vitória (CPV), Centro de Defesa de Direitos Humanos da Serra (CDDH) e Associação Capixaba de Proteção ao Meio Ambiente (Acapema). Contrariando visões dicotômicas da relação sociedade civil e Estado, o estudo identifica uma heterogeneidade de inter-relações em termos de cooperação, conflito e autonomia. A análise estabelece correlações entre os padrões de interação socioestatal e os efeitos institucionais, seja do engajamento em instituições participativas seja das conexões com instituições na gênese do movimento.

Palavras-chave: Movimentos sociais. Instituições participativas. Institucionalização. Interações socioestatais.

\section{Introdução}

Este artigo analisa a reconfiguraçáo das relaçóes entre movimentos sociais e Estado - interaçôes socioestatais -, com base na comparaçáo entre quatro movimentos sociais no Espírito Santo. Argumenta-se que, no contexto pós-transiçâao e de multiplicação das instituiçóes participativas, certos movimentos sociais se engajam institucionalmente em agências do Estado em atividades de elaboraçáo e implementação de políticas públicas; e que essa incorporaçáo pode se diferenciar qualitativamente da trajetória tradicional de

I Doutora em Ciência Política (USP). Professora do Programa de Pós-Graduação em Ciências Sociais da Universidade Federal do Espírito Santo (UFES). Pesquisadora do Núcleo Participação e Democracia (NUPAD) da UFES e do Núcleo Democracia e Ação Coletiva (NDAC) do Centro Brasileiro de Análise e Planejamento (CEBRAP). E-mail: euzeneiacarlos@gmail.com.

2 Versão preliminar deste artigo foi apresentada no $38^{\circ}$ Encontro Anual da Anpocs, realizado de 27 a 31 de outubro de 2014 na cidade de Caxambu, Minas Gerais. Agradeço pelos comentários a Marisa von Bülow e ao parecerista anônimo de Política E Sociedade. 
institucionalização de movimentos sociais caracterizada pela cooptação e pela eliminação do conflito.

O engajamento de movimentos sociais na política institucional, denominado "engajamento institucional", consiste na sua inserção nas Instituiçóes Participativas (IPs), contexto no qual as relaçóes entre sociedade civil e Estado não compreendem um evento pontual e episódico, mas um processo relativamente estável que define as políticas públicas nos dias atuais (CARLOS, 2012, 2015b). As IPs constituem "formas diferenciadas de incorporação de cidadáos e associaçóes da sociedade civil na deliberação sobre políticas" (AVRITZER, 2008, p. 45), mediante os quais cidadáos interferem nas decisões, implementação e acompanhamento de políticas públicas (PIRES; VAZ, 2010).

Este artigo analisa os efeitos do engajamento institucional de movimentos sociais em IPs, como principal hipótese explicativa das mudanças nos padróes de interação socioestatal. Especificamente, considera os múltiplos formatos das instituiçóes participativas como variável independente - conselhos gestores, orçamentos participativos, conferências setoriais, comissóes e comitês temáticos, além de convênios e programas governamentais de gestáo e implementação de políticas públicas. ${ }^{3}$ Esse procedimento metodológico decorre da pressuposição de que a institucionalização dos canais de mediação da relação sociedade-Estado gera implicaçóes sobre a ação coletiva, seja em termos de constrangimentos seja de oportunidades.

Em acréscimo, os efeitos institucionais sobre os padróes de interação socioestatal são examinados a partir de uma segunda hipótese. Nesse caso, avalia a correlaçáo entre os padróes de interaçáo e a gênese relacional dos movimentos, em termos de conexôes com instituições partidárias e religiosas na fundação do ator. Afinal, a rede de relaçóes pregressa do movimento pode afetar o seu padrão de interação com o Estado no contexto democrático.

Neste artigo, o exame das interaçóes socioestatais se estrutura a partir da crítica a uma visão dicotômica da relação sociedade civil e Estado e busca

3 Vale ressaltar que, neste estudo, as IPs incluem além dos arranjos participativos comumente associados, como orçamento participativo, conselhos gestores e conferências setoriais, também os convênios e programas governamentais geridos por organizações da sociedade civil, pelo seu caráter societário. Desse modo, o fenômeno do engajamento institucional se refere à atuação de movimentos sociais - seja nos formatos de IPs, seja nos convênios e programas governamentais. 
demonstrar que essa relação se dá de maneira multifacetada e complexa, em termos de cooperação, conflito e autonomia. Tal análise se baseia no pressuposto de mútua constituição entre atores sociais e instituiçóes políticas, como esferas que interagem e se influenciam mutuamente em um processo contínuo e circunstancial (SKOCPOL, 1992).

$\mathrm{O}$ artigo segue estruturado em seis partes. Após esta breve introdução, a segunda seção apresenta os procedimentos metodológicos aplicados à análise empírica. A terceira não só discute a relação entre movimentos sociais e Estado nas teorias dos movimentos sociais mas também atualiza o debate a partir das contribuiçóes da literatura nacional recente, atenta para as interaçóes socioestatais no contexto de institucionalização da participação. A quarta caracteriza os estudos de casos comparados, em suas trajetórias de emergência e gênese relacional, na década de 1980, e de engajamento institucional pós anos 1990. A quinta seção compóe a análise comparada dos padróes de interação socioestatal. Por fim, discute as interaçóes cooperativas e as conflituais e sua associação com as duas hipóteses elencadas: o engajamento institucional e a gênese relacional dos movimentos.

\section{Procedimentos metodológicos}

O estudo das interaçôes socioestatais considera, como unidade de análise, quatro organizaçóes de movimentos sociais localizadas na regiáo metropolitana do Espírito Santo, quais sejam: Federação das Associaçóes de Moradores da Serra (Fams), Conselho Popular de Vitória (CPV), Centro de Defesa de Direitos Humanos da Serra (CDDH) e Associação Capixaba de Proteção ao Meio Ambiente (Acapema). ${ }^{4}$

Examinados por meio do método comparativo de estudo de casos (PETERS, 1998; GEORGE; BENNETT, 2004), a análise desses movimentos foi processada em dois níveis: 1) comparação intertemporal (cross-time), e 2) comparação entre os casos (cross-case). A comparação cross-time das trajetórias dos movimentos ao longo de um continuum intertemporal de três décadas (1980-2010), considerou a variação nos padróes de interação socioestatais

4 Ainda que o movimento social não seja restrito à sua organização formal e abarque uma multiplicidade de atores sociais, individuais e organizacionais em interações informais (DIANI, 2003), em virtude do escopo comparativo deste estudo, o foco empírico ou a unidade de análise é a organização do movimento. 
em dois contextos analíticos, denominados Tempo 1 (T1) e Tempo 2 (T2). Compreende o T1 o contexto de redemocratizaçáo da década de 1980, e o T2, o período de criação das IPs nos governos, sobretudo a partir de 1990 . A comparação cross-case, por sua vez, possibilitou a verificação das regularidades nos padróes, ao mesmo tempo em que dimensionou as variaçóes na ação dos movimentos.

O exame das regularidades e variaçóes nos padróes de interação, em ambos os níveis de comparação, foi controlada por uma compreensão densa dos casos, favorecida por perspectiva multi-method, que conduziu a um desenho de pesquisa que combinou instrumentos do método qualitativo e quantitativo, a saber: 1) pesquisa documental no acervo das organizaçóes dos movimentos; 2) entrevista em profundidade com atores-chave; e 3) survey de questionário semiestruturado aplicado a 100 militantes, selecionados por meio de amostra náo aleatória que considerou a posiçáo de centralidade do ator no movimento. $\mathrm{Na}$ análise geral, os dados provenientes dos diferentes instrumentos metodológicos foram agrupados em torno de temas, a fim de verificar a triangulação das evidências e promover a validaçáo dos resultados a partir de linhas convergentes de investigação.

\section{A relação entre movimentos sociais e Estado: das teorias dos movimentos sociais ao debate nacional recente}

A reconfiguração das relaçóes entre movimentos sociais e Estado no Brasil pós-transição tornou-se um foco de problematização teórica, investigação empírica e de deslocamentos analíticos (SILVA, 2010; GURZA LAVALLE; SZWAKO, 2015). Em face das múltiplas possibilidades de interação dos movimentos sociais com o Estado, como as Teorias dos Movimentos Sociais (TMS) explicam o engajamento societário nas instituiçóes estatais? Como essas teorias analisam tais mudanças nas relaçóes socioestatais e suas implicaçóes para os movimentos sociais?

As Teorias dos Movimentos Sociais, a despeito de suas contribuiçóes diversas na explicação dessas coletividades, não ofereceram instrumentos conceituais e metodológicos para explicar as relaçóes dos movimentos sociais com governos, agências estatais ou partidos políticos, assim como a natureza dessas 
inter-relaçóes e de seus efeitos para os atores e as políticas implicadas. ${ }^{5}$ Por um lado, a teoria do Processo Político enfatizou a ação coletiva como conflito político com os "detentores de poder" (MCADAM; TARROW; TILLY, 2001; TARROW, 1997); por outro, a dos Novos Movimentos Sociais ressaltou a sua descontinuidade com as modalidades tradicionais da política (MELUCCI, 1996; TOURAINE, 1985). Essas teorias partem de um modelo dicotômico de ação que tende a associar a interação com o Estado a um processo de "institucionalização do movimento".

A teoria do processo político desenvolveu as abordagens mais influentes acerca da institucionalização do movimento, concebida como a sua integração às estruturas do Estado, a mudança no repertório de confronto e a busca de benefícios concretos através da negociação e acordo (TARROW, 1997; MCADAM; TARROW; TILLY, 2001). Nesse enfoque, a institucionalizaçáo do movimento produz efeitos de complexificação em sua estrutura organizacional, expressos pela rotinização, burocratização e profissionalização da ação coletiva (MEYER; TARROW, 1998; KRIESI, 1999; PIVEN; CLOWORD, 1979; MCCARTHY; ZALD, 1973). A complexificação organizacional traria como consequências a mudança em seus objetivos de fundação, a desmobilização dos militantes, a cooptação dos ativistas e a sua transformação em grupos de interesse ou partidos políticos. Essas análises restringem os efeitos destas inter-relaçóes às estruturas organizacionais dos movimentos e consideram, em geral, um único modelo de organização. Destacam-se aqui três elementos desta abordagem, prejudiciais à compreensão das interconectividades entre atores coletivos e instituiçóes e dos efeitos da institucionalização.

Em primeiro lugar, as teorias dos movimentos sociais pressupóem uma separação entre estes e a política institucionalizada e analisam a sociedade e o Estado a partir de categorias estanques, autônomas e dicotômicas. A separação analítica rígida entre sociedade e Estado restringe a compreensáo dos movimentos em processos de interaçáo com atores institucionais, pois dificultam o reconhecimento do seu caráter mutuamente constituinte, de influência mútua e de interpenetração. Conformem apontam Abers e Von Bülow (2011), essa suposição inibe estes teóricos de explorar a diversidade de conexóes

5 Para uma discussão ampliada das teorias dos movimentos sociais e de suas limitações à explicação das relações desses com o Estado, vide: Carlos, $2015 \mathrm{c}$. 
entre movimentos sociais e o sistema político, mantendo invisíveis certos tipos de relaçóes entre atores coletivos e o Estado. A despeito de sua valorização das condiçóes político-institucionais para a emergência dos movimentos, essa abordagem enublou as interaçóes que estabelecem coletividades e instituiçóes políticas e sequer problematizou os termos de sua mútua constituiçáo.

Neste artigo, assume-se o pressuposto de que a relaçáo entre movimentos sociais e instituiçôes políticas é contingente e mutuamente constitutiva, cujas implicaçôes ou efeitos decorrentes são produzidos sobre ambos os atores societários e institucionais. Desse modo, a relaçáo entre os movimentos sociais e as instituiçóes requer uma compreensão dinâmica que acentue a mútua constituição entre a sociedade e o Estado, como esferas que interagem e se influenciam mutuamente em um processo contínuo e circunstancial (SKOCPOL, 1992). A fronteira entre política não institucionalizada e política institucionalizada é pouco clara, afirma Goldstone (2003). Na análise dos impactos dos movimentos na gênese de partidos políticos e na formação de governos de esquerda, esse estudioso acentua o processo de imbricação entre instituiçóes do Estado, partidos políticos e movimentos sociais, mediante o qual a estrutura das instituiçóes e a dos movimentos sociais são mutuamente influenciados (GOLDSTONE, 2003). Essa perspectiva é particularmente relevante à análise de movimentos que interagem com instituiçóes do Estado. Ao contrário, as perspectivas dicotômicas e dualistas dificultam o reconhecimento das interaçóes mutuamente constitutivas entre o movimento e as instituiçóes políticas e da combinação circunstancial, pelas coletividades, das modalidades de ação outsider e insider.

Em segundo lugar, as TMS se baseiam em um modelo conflituoso de ação que restringe a análise da relação entre os movimentos sociais e o Estado, no contexto de institucionalização dos canais de mediação. Prepondera nesse enfoque da relação entre movimentos sociais e sistema político a contestação das instituiçóes políticas, e não as interaçóes com o Estado e os detentores de poder (JENKINS, 1995). Ainda que o Estado tenha recebido centralidade nesse modelo analítico, os estudiosos sublinham as oportunidades políticas e sociais sob as quais "desafiadores" contestam o poder na arena político-institucional (TARROW, 1997; TILLY, 2004). Nessa abordagem, a relação dos movimentos com a institucionalidade política compreende a sua integração 
ao sistema, evidenciada particularmente pelo reconhecimento dos movimentos como atores políticos e pela obtenção de seus objetivos demandados ao Estado. Assim sendo, o caráter contestatório e desafiador dos movimentos em direção aos detentores de poder é compreendido em termos de um modelo conflituoso de açáo, construído dentro das relaçóes de poder do sistema político e que implica conflito de interesse entre atores não institucionais e institucionais.

Dentre outras implicaçóes, sob essa perspectiva, as possibilidades de relaçôes dos movimentos com o Estado são reduzidas e circunscritas às interaçôes de poder conflituosas, desprivilegiando aquelas interaçóes cooperativas ou colaborativas entre atores societários e institucionais em torno da produção de políticas públicas ou de alianças com partidos políticos (GOLDSTONE, 2003; GIUGNI; PASSY, 1998; HANAGAN, 1998). De acordo com Giugni e Passy (1998), ainda que a visão de movimentos sociais como uma forma especifica de contentious politics náo deva ser abandonada, é preciso admitir que movimentos sociais se engajam em um conjunto de atividades que náo necessariamente implica uma relaçâo de conflito com os detentores de poder. Conforme argumentam os autores, em sociedades complexas, movimentos também cooperam com o Estado, especialmente na solução de problemas públicos, na elaboração e na implementação de políticas. Desse modo, os movimentos sociais “[...] intervém nos processos políticos de duas formas: desafiando as políticas ou propostas existentes e colaborando na elaboração e implementação de políticas governamentais" (GIUGNI; PASSY, 1998, p. 82).

É mister destacar que os autores definem a cooperação a partir do nível pragmático da concordância, isto é, quando a relação de colaboração se converte em açôes concretas, sob três formas: consulta, quando os atores não institucionais colaboram com informaçóes relevantes à tomada de decisóes; integração, quando os atores agem na implementação de decisóes mediante a atuação em comitês, grupos de trabalho ou agências governamentais; e delegação, quando o Estado transfere a responsabilidade para o movimento no nível operacional. Em outras palavras, a cooperação se estabelece no plano da solução de problemas sociais e da contribuiçãa com o Estado na elaboração, implementação ou execuçáo de políticas públicas, em que movimentos sociais 
colaboram com o seu conhecimento e informação sobre determinada política pública. ${ }^{6}$

Em terceiro e último lugar, nas TMS a análise da institucionalização do movimento social opera sem introduzir uma distinção que lhe é fundamental, qual seja, entre a institucionalização do canal de mediação com o Estado e aquela do movimento. Isso, pois, a institucionalizaçáo do canal de mediaçáo não significa aprioristicamente a institucionalização do ator. Tal compreensão torna-se, portanto, inábil para objetar em que medida a primeira geraria características institucionais no comportamento do ator, assim como para captar as regularidades e variaçóes nos efeitos da relação entre as instituiçóes e os atores sociais. Por esse motivo, é necessário submeter à verificação empírica os efeitos das interaçóes socioestatais, pois, entre outras razóes, o movimento pode ser altamente organizado, formalizado e profissionalizado também nos ciclos de protesto público, mesmo que sob o manto de narrativas de espontaneidade.

Em particular, a ênfase desta teoria na estrutura organizacional do movimento conduziu a uma noção estreita de institucionalização definida em termos de complexificação organizacional, a qual é remetida à rotinização, previsibilidade, formalização, profissionalização, desmobilização e oligarquização da ação coletiva. Essa perspectiva assume visão homogeneizante dos modelos de institucionalização. Por um lado, desconsidera a diferenciação nos padróes organizacionais, tendo em vista as situações de combinaçáo entre complexificação organizacional e mobilização, em processos de engajamento em instituiçóes de formato inovador (CARLOS, 2012, 2015a, 2015b). Por outro lado, ocultam as relaçóes complexas e multifacetadas dos movimentos com o Estado, caracterizadas pela combinaçáo de elementos aparentemente contraditórios, como a cooperação e o conflito (CARLOS, 2012, 2015a, 2015b) e a autonomia decisória (TATAGIBA, 2010; SZWAKO, 2012). Nessa perspectiva, a autonomia é entendida como a "[...] capacidade de determinado ator de estabelecer relaçóes com outros atores (aliados, apoiadores e antagonistas) a partir de uma liberdade ou independência moral que lhe permita codefinir as formas, as regras e os objetivos da interação, a partir dos seus interesses e valores" (TATAGIBA, 2010, p. 68).

6 A relação de colaboração entre sociedade civil e Estado também é descrita sob o signo da "parceria", caracterizada pelo uso de fundos públicos para o desenvolvimento das atividades dessa primeira e pela intensificação da sua interlocução com atores institucionalizados (Vide: REIS, 2013; PENNA, 2015). 
Os estudos brasileiros recentes têm contribuído para a compreensão das interaçóes entre movimentos sociais e instituiçóes. Esses defendem o reconhecimento concomitante da dimensão cultural e institucional dos movimentos e de sua inter-relação com as configuraçôes do Estado, como esferas que interagem e se determinam mutuamente. ${ }^{7}$ Demonstram que, no contexto pós-transição de institucionalização dos canais de mediação, os movimentos sociais combinam uma diversidade de padróes de relação com o Estado que prescindem da desmobilização (CARLOS, 2015b), incluindo táticas institucionalizadas como a ocupaçáo de cargos públicos (DOWBOR, 2012). Em complemento, Silva e Oliveira (2011) demonstram que padróes complexos de relaçóes entre sociedade civil e Estado, mediadas por partidos políticos de esquerda, constituem um "trânsito institucional" que favorece a institucionalizaçáo de demandas do movimento. Ao contrário das interpretaçóes de negaçáo e externalidade em face da institucionalidade política, predominantes no processo de redemocratização do país, esses autores constatam um padrão de intersecção entre movimentos e Estado impulsionado pelo trânsito de militantes para agências governamentais (SILVA; OLIVEIRA, 2011).

Em seu estudo, Abers, Serafim e Tatagiba (2014) demonstram que a variedade de formas de relaçáo dos movimentos sociais com o Estado compreende "repertórios de interaçáa", no qual se inclui um conjunto de rotinas - protesto, participaçáo institucional, política de proximidade e ocupaçáo de cargos públicos. Conforme explicam as autoras, os repertórios de interação “[...] permitem uma combinação criativa de tradiçôes históricas de interação Estado-sociedade em modos que promoveram novas formas de negociação e diálogo" (ABERS; SERAFIM; TATAGIBA, 2014, p. 346). A compreensão da multiplicidade de modalidades de interação do movimento social com o Estado constitui relevante contribuição à literatura. Dentre outras, isso indica que, nas diferentes interfaces socioestatais, o movimento combina o engajamento em instituições participativas com uma diversidade de repertórios de atuação, na finalidade de direcionar as suas demandas ao Estado e influir na agenda política. Explicar as diversas modalidades de interdependência nas interaçóes

7 Ao contrário, na literatura brasileira do periodo de transição democrática a interpretação sobre a relação entre movimentos sociais e Estado gravitou em torno da polarização "autonomia versus institucionalização". Para uma revisão crítica, vide: Carlos, 2015 c e Paoli, 1995. 
socioestatais e avaliar as suas consequências para os atores e as políticas, constitui importante desafio para esta agenda de pesquisa (GURZA LAVALLE; SZWAKO, 2015). ${ }^{8}$

Conforme dito, os modelos dualistas e homogeneizantes de ação coletiva não oferecem instrumentos conceituais e metodológicos adequados para explicar as relaçóes complexas e multifacetadas entre movimentos sociais e Estado. Por sua vez, as análises recentes vêm oferecendo avanços à temática das interaçôes socioestatais e de suas implicaçóes, cujos deslocamentos teóricos se ancoram na busca da incorporação sistemática do Estado e das instituiçóes, dos partidos políticos inclusive, nos quadros analíticos dos movimentos sociais.

Com essa finalidade, a análise das interações entre movimentos e Estado é favorecida pela perspectiva de "interface socioestatal" desenvolvida por Isunza Vera, a qual constituiu um "[...] espaço de intercâmbio e conflito em que os atores se relacionam intencionalmente, e onde se chocam projetos, forças e estratégias dos atores (estatais e societais) envolvidos" (ISUNZA VERA, 2006, p. 263). De acordo com o autor, as interfaces socioestatais estão determinadas estruturalmente tanto pela política pública em que se inserem quanto pelos projetos políticos dos atores implicados. Nas interfaces os atores societais e estatais, com diferentes intençóes e papéis atribuídos, reconfiguram o conteúdo de suas interaçóes e desenvolvem lógicas de intercâmbio mediadas pela troca de informação e poder. Desse modo, o conceito remete à ideia de um espaço constituído por sujeitos intencionais, "cujas relaçôes - na maior parte das vezes - assimétricas com outros sujeitos estabelecem um espaço de conflito, de negociação e disputa" (ISUNZA VERA; GURZA LAVALLE, 2012, p. 109).

De modo geral, este conceito contribui para a descrição e a explicação das interaçôes entre os movimentos sociais e o Estado. Isto pois, em primeiro lugar, a noção de interface socioestatal assume a necessidade de analisar as relaçóes entre movimentos e Estado desde uma perspectiva do ator, sem desconsiderar as dimensôes institucionais e das políticas públicas implicadas. Em segundo lugar, essa noção reconhece os atores societários e estatais como politicamente relevantes no processo de políticas públicas. E, em terceiro, ao

8 Para uma análise dos efeitos das interações entre movimentos sociais e Estado sobre os padrões de ação coletiva, vide: Carlos, 2015b, 2012. Os impactos destas relações socioestatais sobre o Estado foram examinadas por Abers e Keck (2013), e sobre a política pública de habitação por Tatagiba e Teixeira (20I6). 
enfatizar a intencionalidade dos sujeitos sociais e estatais nas suas interaçóes - seus projetos político-culturais, funções e papéis - reconhece a possibilidade tanto de diferenciaçáo quanto de similaridade de perspectivas dos atores políticos envolvidos. Conforme acentuam Pires e Vaz (2014), essa noção de interface socioestatal oferece um escopo analítico mais amplo que outros arcabouços conceituais, capaz de incorporar a complexidade das relaçóes entre Estado e sociedade no Brasil das últimas décadas.

Este artigo discute as interaçóes entre movimentos sociais e Estado na elaboraçáo e implementação de políticas públicas, considerando este enfoque relacional das interfaces socioestatais, em complemento às TMS. Com esse propósito, as interaçôes socioestatais serão examinadas em seu conteúdo e significado para os atores coletivos, com base na comparação entre quatro organizaçóes de movimentos sociais, bem como seráo alçadas as condiçóes subjacentes deste processo político.

\section{Os casos Fams, CPV, CDDH e Acapema}

\section{Trajetórias de emergência e gênese relacional}

As organizaçóes de movimentos sociais analisadas insurgiram no contexto de transição do regime autoritário da década de 1980. A Fams e o CPV, autodenominados "movimento popular", emergiram com a finalidade de organizar, coordenar e fortalecer o movimento de bairro e reivindicar melhorias sociais e urbanas ao poder público municipal, o primeiro na Serra em 1981, e o segundo em Vitória, em 1986. Atualmente, possuem uma estrutura federativa com 125 e 124 associaçóes de moradores, respectivamente, e suas principais realizaçóes correspondem a setores das políticas sociais, nas áreas de saúde, infraestrutura urbana, transporte coletivo, educação, moradia e meio ambiente, além da criaçáo de IPs na gestáo pública. Sua gênese relacional, entendida como rede de relaçóes sociais pregressa ou fundacional, era composta por Comunidades Eclesiais de Base (CEBs), partidos políticos de esquerda, sobretudo o Partido dos Trabalhadores (PT), sindicatos trabalhistas, comissóes de direitos humanos, grupos de mulheres e de jovens, Equipe de Apoio aos Movimentos Populares e ONGs, como a Fase (Federação de Órgãos para Assistência Social e Educacional) e o Cecopes (Centro de Educação e Comunicação Popular D. João Batista), além das associaçóes comunitárias filiadas. 
O CDDH, uma organização do Movimento Nacional de Direitos Humanos (MNDH), também surgiu no município da Serra, em 1984, na finalidade de coordenar a ação mobilizatória de outros movimentos sociais e organizaçóes civis, atuando na defesa dos direitos humanos e fomentando a criação de associações de moradores, sindicatos trabalhistas e outras formas de organização popular, em nível local e regional. $\mathrm{O} \mathrm{CDDH}$ foi inicialmente criado como Comissão de Direitos Humanos da Igreja Católica e composto por integrantes das CEBs e militantes de movimentos locais, sobretudo pastorais sindicais e associaçóes de moradores. Suas conquistas compreendem áreas das políticas de direitos humanos, como criança e adolescência, violência, saúde, educação, moradia, bem como a implementação de IPs nos governos municipal e estadual. Promoveu diversas açóes unificadas entre forças sociais e políticas que compunham sua rede de relaçóes pregressa, articulando com segmentos da Igreja Católica como o Conselho Pastoral de Carapina (Copaca), a Fams, o PT, sindicatos do "novo sindicalismo", ONGs, associaçóes comunitárias e outros movimentos de direitos humanos.

Por sua vez, a Acapema, fundada em Vitória em 1979, constitui uma organizaçáo do movimento ambientalista de âmbito regional. Atua na articulaçáo e promoçáo de campanhas mobilizatórias em prol da manutençáo do equilíbrio ecológico e na oposição aos grandes projetos de expansão industrial e desenvolvimento econômico, no fomento à criação de unidades de conservação ambiental e na criação e cumprimento de legislação de caráter conservacionista. À época de sua fundação, estabeleceu vínculos com ampla rede de relaçóes sociais, a qual constituiu fonte de suporte e apoio às açóes desenvolvidas, caracterizada, sobretudo, pela interação com entidades civis e movimentos sociais e, em menor proporção, com instituiçóes do sistema político, como segmentos religiosos e partidos políticos.

Neste contexto de emergência, foi convergente na gênese dos movimentos seus princípios discursivos, quer no ideário de transformação social quer no de democracia interna quer ainda no de autonomia na relaçáo com instituiçóes do Estado e partidos políticos. Nesse último aspecto, embora a autonomia dos movimentos em face do sistema político fosse discursivamente defendida pelos sujeitos coletivos, muitos deles desenvolveram interaçóes com setores da Igreja Católica (DOIMO, 1995) e com partidos políticos de 
esquerda (SADER, 1988). A relação dos movimentos sociais com os partidos políticos fora marcada por tensóes e ambiguidades. Especialmente nos casos da Fams, CPV e CDDH, a relaçáo com partidos políticos de esquerda, ora mediada por afinidade ideológica ora por interesse em aliança política, aponta um padrão seletivo e intermediado pelo potencial de coalizão com vistas à influência na agenda política. Esses movimentos insurgiram frente ao desafio cotidiano de apresentar uma face independente diante do Estado e, ao mesmo tempo, construir apoios e alianças político-partidárias para consolidação dos seus projetos. Em sua gênese, o padrão de interação seletivo com as instituições não reduziu o potencial de oposição e contestaçáo desses movimentos, nem significou a eliminação do conflito diante de segmentos conservadores do Estado. No caso da Acapema, porém, as interaçôes seletivas com instituiçóes religiosas e partidárias fora menos recorrente, tendo esse movimento investido mais na articulaçáo com outras coletividades e organizaçôes sociais. O discurso de hostilidade, antagonismo e de "não relaçáo" com o Estado caracterizou suas práticas no contexto fundacional.

Em acréscimo, a percepção dos militantes de vínculos com grupos religiosos e partidos políticos de esquerda no contexto fundacional, sobretudo Igreja Católica e PT, prepondera entre os casos analisados: na Fams, atinge $92 \%$ referente à instituição religiosa e $85 \%$ a partidos políticos de esquerda; no CPV alcança $74 \%$ quanto a grupos religiosos e $70 \%$ quanto aos vínculos com partidos políticos; no CDDH, a percepção atinge $100 \%$ dos militantes acerca de segmentos religiosos e $96 \%$ quanto a partidos políticos de esquerda. Comparativamente, a percepção dos ativistas da Acapema de relaçôes com ambas as instituiçóes é menos significativa: a crença de vínculos com grupos religiosos na fundação do movimento é de $32 \%$ e com partidos políticos não ultrapassa $16 \%{ }^{9}$

Em suma, os movimentos sociais se diferenciam conforme a gênese relacional. Ao contrário da Acapema, a rede de relaçóes sociais pregressa da Fams, $\mathrm{CPV}$ e CDDH é composta por múltiplas organizaçôes tanto institucionais

9 Fonte: Survey da pesquisa Movimentos Sociais e Instituições Participativas (20/2).

Nota: Resposta múltipla à pergunta induzida: Com quais entidades, movimentos sociais ou instituições a [OMS] manteve relações? Percentual de respostas segundo o total de respondentes: Fams $(N=26)$, CPV $(N=27)$, $\mathrm{CDDH}(\mathrm{N}=24)$ e Acapema $(\mathrm{N}=19)$ 
quanto societárias: de um lado, vínculos com instituiçóes religiosas e partidárias, de outro, laços com sindicatos trabalhistas, movimentos sociais e entidades da sociedade civil. É mister ressaltar o caráter informal, descentralizado e não institucionalizado dessas relaçóes, em grande medida, articuladas por "ativistas multifiliados" (MISCHE, 2003) que se engajam e entrecruzam entre movimentos e instituiçóes.

Para os propósitos deste artigo, a interação de movimentos sociais com instituiçôes do Estado no contexto de fundação, como a Igreja Católica e o PT, aumenta a sua propensão a interagir com instituiçóes políticas no contexto democrático. Isso, porque essas funcionam como "incubadoras institucionais" para o movimento social conflituoso, favorecendo o aprendizado institucional dos movimentos e o reconhecimento da legitimidade dos atores institucionais (HOUTZAGER, 2004).

\section{Trajetórias de engajamento institucional}

No Brasil pós-transição é notório um processo de engajamento institucional, caracterizado pela atuação de movimentos sociais e ativistas na formulação e implementação de políticas públicas. Subjazem esse fenômeno a multiplicaçáo de instituiçóes participativas nos três níveis de governo, bem como a gestão de convênios e programas governamentais por organizações da sociedade civil.

No intuito de mensurar o nível de engajamento institucional dos movimentos analisados, o exame partiu de critérios de densidade, diversidade, durabilidade e deliberação. $\mathrm{O}$ primeiro diz respeito à quantidade de IPs em que se inserem os movimentos, quais sejam, orçamento participativo, conselhos gestores, fóruns ou conferências setoriais, comissóes ou comitês, convênios e programas governamentais; o segundo corresponde à pluralidade ou variedade das áreas de políticas públicas e de formatos de participação institucionalizada; o terceiro identifica a continuidade ou interrupção da inserção dos movimentos sociais em IPs, possibilitando avaliar a relação entre essa permanência e a intensidade do seu engajamento nas agências dos governos; por fim, o critério deliberaçâo considera a possibilidade dos movimentos de sustentar posiçóes e propostas nos arranjos participativos frente aos representantes governamentais e de efetivamente deliberar nesses espaços, enquanto um elemento que qualifica seu nível de engajamento institucional. 
A análise comparada dos movimentos sociais nessas dimensóes aponta a existência de dois subgrupos: o primeiro, formado pela Fams, CPV e CDDH; o segundo, pela Acapema. Considerando a quantidade de IPs que atuam, ou seja, a densidade da sua participaçáo, o primeiro grupo apresenta alta densidade e o último, uma baixa densidade. A Fams possui representação em 16 conselhos gestores; o CPV, em 24; o CDDH, em dez, dos quais dois sáo estaduais. Esses três movimentos participam, ainda, do orçamento participativo e de outras esferas institucionalizadas de participação e representação. Segundo essa medida, a Acapema apresenta baixa densidade nas IPs, atuando em apenas um conselho de políticas em nível municipal e três no âmbito estadual. ${ }^{10}$

Os conselhos gestores de atuaçáo da Fams e do CPV compreendem significativa variedade nas áreas de políticas públicas (saúde, educação, meio ambiente, política urbana, habitação, turismo, segurança, assistência social, cultura, direitos de gênero e etário, entre outras). No caso do $\mathrm{CDDH}$, as áreas de políticas públicas também são diversificadas (saúde, assistência social, direitos da mulher, do idoso, da pessoa com deficiência, cidade, antidrogas, segurança alimentar, direitos humanos e gestão de segurança pública). Ao contrário desses, a Acapema atua somente nas áreas de meio ambiente e de saúde, retratando um caso de baixa diversidade das IPs.

O critério de diversidade considera, por fim, a variedade dos formatos das IPs de inserção societária. Esse componente é particularmente inovador, pois enfatiza a multiplicidade de formas institucionalizadas de participação que incentivam o engajamento de movimentos sociais e atores da sociedade civil na esfera estatal. No caso dos movimentos que se caracterizam por alta diversidade de IPs (Fams, CPV e CDDH), seu engajamento ocorre não somente nos arranjos participativos comumente enfatizados, como os conselhos de políticas públicas, o orçamento participativo e as conferências setoriais, mas também envolve outros formatos de atuaçáo institucional, como o plano diretor urbano e o plano plurianual participativo, as comissóes e os comitês temáticos

10 No município da Serra, as IPs foram introduzidas a partir de 1997, pela coligação partidária PDT-PT-PSB que seguiu por quatro mandatos consecutivos (I997 a 2012). Em Vitória, por sua vez, os arranjos participativos foram implementados pelo governo do PT (1989-1992), seguido por três governos do PSDB (1993 a 2004) e, posteriormente, por duas gestões do PT (2005 a 20I2). No governo estadual, os arranjos participativos foram criados, sobretudo, a partir da gestão do PT (1995-1998), seguida pela do PSDB (1999-2002), do PMDB (20032006) e por duas gestões do PSB (2007 a 2014). 
e os convênios governamentais de implementação e gestão de programas de políticas. Por sua vez, na Acapema, a atuação institucional é circunscrita aos conselhos de políticas públicas e conferências setoriais, caracterizando, comparativamente, um movimento de baixa diversidade dos arranjos institucionalizados de participaçáo.

No que se refere ao critério de durabilidade, a inserção dos movimentos em instituiçóes participativas é avaliada segundo sua longevidade em quatro e seis gestóes governamentais, qualificada em termos de durabilidade continuidade e descontinuidade. A aplicação desse critério mantém a classificação dos movimentos focada em dois subgrupos anunciados. O primeiro, em geral, caracteriza uma inserção contínua e sem interrupções nos arranjos participativos ao longo do tempo, ao passo que o segundo apresenta uma durabilidade descontínua que, embora guarde relação com os projetos políticos governamentais, é justificada pelos militantes pela baixa efetividade dessas instâncias na concretização de seus objetivos.

Por fim, o componente deliberação complementa os critérios de mensuração do nível de engajamento institucional dos movimentos em IPs. A análise da possibilidade de deliberar efetivamente nesses espaços, medida em termos de grau de satisfaçáo, aponta no primeiro subgrupo a avaliaçáo de "regularmente satisfeito". No caso da Acapema, prevalece entre os militantes a percepção de "pouco satisfeito". De modo geral, os militantes argumentam que essas avaliaçóes das limitaçóes em sustentar suas posiçóes e decisóes no debate público dos arranjos institucionalizados de participação se devem a dois fatores principais, a saber: o descumprimento do governo de muitas deliberaçóes dos representantes societários e a fragilidade decisória do movimento nessas esferas públicas.

Em resumo, os movimentos sociais se diferenciam conforme o nível de engajamento institucional. Comparativamente, a Fams, o CPV e o CDDH caracterizam um engajamento institucional de alta intensidade, na medida em que as instituiçóes participativas em que atuam retratam densidade e diversidade altas, durabilidade contínua e deliberaçáo regular. Por sua vez, a Acapema caracteriza um movimento de engajamento institucional de baixa intensidade, visto que os seus arranjos participativos são de densidade e 
diversidade baixas, de durabilidade descontínua e de deliberaçáo baixa. Neste artigo, o engajamento institucional é correlacionado aos padróes de interação com o Estado, pois se pressupóe que a institucionalização dos canais de mediação gera efeitos sobre a ação coletiva.

\section{Interações socioestatais no contexto de engajamento institucional: entre a cooperação e o conflito}

No Brasil pós-transição, contexto de engajamento de movimentos sociais nas instituiçôes participativas e agências governamentais, a relação desses com o Estado demonstra a configuração de diversos padróes, em termos de cooperação, conflito e autonomia; não obstante, realçam, predominantemente, padrôes de interação cooperativos (CARLOS, 2012, 2015b). Conforme Guigni e Passy (1998) e Goldstone (2003), os movimentos sociais podem não somente desafiar os detentores de poder, mas também estabelecer uma relação cooperativa com autoridades políticas e agências do Estado. As relaçóes entre movimentos sociais e Estado são complexas e multifacetadas, as quais envolvem além do conflito, a colaboração na elaboração e implementação de políticas públicas.

O estabelecimento desta nova concepçáo de relação com o Estado ocorreu em prejuízo das categorias de antagonismo e oposição, outrora influentes, e da ascensáo das de cooperaçáo, parceria, proximidade e diálogo. De acordo com Giugni e Passy (1998, p. 84), a cooperação compreende "[...] a relação entre duas partes baseada na concordância quanto aos fins de uma dada ação, que envolve uma colaboração ativa com o objetivo de atingir cada finalidade". Todavia, segundo os autores, três ressalvas são necessárias nessa noção de cooperação: (i) a concordância quanto aos fins da ação raramente é completa, dada a assimetria de poder e de interesses entre os atores societários e os estatais; (ii) a cooperação com o Estado não é extensiva ao nível do consenso quanto às políticas governamentais; (iii) os movimentos são ambivalentes e utilizam uma estratégia de combinação do conflito e cooperaçáo, denominada “cooperação conflitual” (GIUGNI; PASSY, 1998, p. 84).

Neste bojo, o padrão de cooperação na relação sociedade-Estado tornou-se emergente, especificamente na Fams, no CPV e no CDDH. O padrão de interaçáo cooperativo dos movimentos com a esfera estatal é caracterizado pelo 
estabelecimento de relações de colaboração e parceria na elaboração de políticas públicas e na implementação e execução de projetos e programas específicos do governo. Para essas coletividades (Fams, CPV e CDDH), a relação de cooperação e colaboração com o Estado favorece o resultado de suas açôes, na medida em que, com acesso aos órgãos públicos e a espaços institucionais, os atores societários alcançam o reconhecimento da sua legitimidade. Em outros termos, relaçóes de proximidade e cooperação com os governos sáo relevantes ao atendimento das reivindicaçóes do movimento, ao estabelecimento do diálogo e da proposição, à representação e à participação nas instituiçôes participativas, à discussão, à fiscalização, ao acompanhamento de políticas públicas e à gestão de programas e convênios governamentais. Em suma, as interaçóes colaborativas têm como consequências o atendimento a demandas históricas do movimento e a sua influência política na agenda pública. Por outro lado, a ampliação da influência dos movimentos sociais depende da habilidade dos atores coletivos em manter sua autonomia política. Isso porque o exacerbamento da cooperação pode gerar o excesso de comprometimento e vínculos institucionais com o Estado, reduzindo sua potencial capacidade de pressão e influência e favorecendo a dependência dos atores coletivos.

Os militantes reconhecem que relaçóes colaborativas com o governo os expóem a riscos que dificultam um comportamento crítico e autônomo: risco de dependência e submissão, de atrelamento e cooptação; de perda da autonomia e de distanciamento da base social; de impedimento de açóes contrárias e críticas ao governo; de vinculação da imagem do movimento com a do governo; e da perda da capacidade de discussão e proposição. Naturalmente, isso náo significa que os modelos cooperativos sejam dependentes a priori. Endossar essa posição, significaria partir de uma compreensão homogênea da ação coletiva, que desconsidera a diversidade das configuraçóes sociais e as possibilidades de invençáo criativa, como ocorre em combinaçóes dicotômicas que assimilam a cooperação à cooptação e contestação à autonomia.

Nos movimentos analisados, o padrão de interaçáo cooperativo comporta ambas as categorias - dependência e autonomia. Na Fams e no CPV, a relação de colaboração com as instituiçóes governamentais tem obstado um posicionamento crítico e independente dos atores coletivos, ainda que os militantes associem esse padrão ao êxito nos resultados das suas açóes e ao acesso à esfera política. Com efeito, dependência, submissão e atrelamento são as categorias 
que traduzem ali uma autonomia frágil, configurando, assim, um "padrão de interaçáo cooperativo e dependente". Vale assinalar que dependência é aqui entendida como a dificuldade de sustentar posiçóes de modo independente dos interesses estatais e da agenda política governamental, mas não se confunde com cooptação, isto é, com a mudança de objetivos dos militantes. No contexto de incentivos à participação institucional "[...] a relação entre movimentos sociais e sistema político é permeada por uma tensão intrínseca entre os princípios da autonomia e a da eficácia política”, conforme ilustra o movimento de moradia (TATAGIBA, 2010, p. 67).

No $\mathrm{CDDH}$, diferentemente, os atores se dizem autônomos em relação ao Estado e, unanimemente, náo correlacionam categorias de dependência e submissão para qualificar sua relação com a esfera governamental. Nesse caso, configura-se, pois, um "padrão de interação cooperativo e autônomo". A priori não há contradição entre cooperação e autonomia, uma vez que essas duas características podem ser combinadas em um mesmo padrão de interaçáo socioestatal; afinal, "institucionalização e independência podem parecer antitéticos, mas podem ser complementares" (DOOWON, 2006, p. 185). A interação de movimentos sociais com a esfera estatal com vistas a influir no processo político não implica, necessariamente, a perda de autonomia decisória, segundo também demonstra o movimento feminista (SZWAKO, 2012).

O padrão de interação cooperativo se distingue, ainda, pela perspectiva de conflito. Os padróes de cooperação não conflitivos são similares aos casos “[...] em que os recursos são combinados para a busca de objetivos práticos específicos, sem uma narrativa que situe os distintos episódios em arcabouços mais amplos, e sem que se desenvolvam identidades mais abrangentes a partir da ação" (DIANI; BISON, 2010, p. 225). Em geral, esses processos são caracterizados pela forte dependência das instituiçóes e pela ausência de um elemento conflituoso que se converta em repertórios de contestação. Esse é o caso da Fams e do CPV, cuja relaçáo de colaboração com o Estado consiste na realização de objetivos específicos, não controversos e subordinados à agenda governamental. Suas interaçóes, mesmo emersas em percepçóes de conflito e desigualdade de recursos e poder, não se consubstanciam em episódios de ação conflitiva enquanto estratégia para influir na agenda pública. Nas últimas duas décadas, foram raras suas manifestaçóes de contestação ao poder público 
local e as estratégias resumidas ao uso de táticas institucionalizadas e formalizadas. Com efeito, os vínculos mais importantes foram estabelecidos com os órgãos públicos responsáveis pelas políticas demandadas.

Porém, o espaço para dinâmicas conflitivas no interior dos mesmos fenômenos gerais pode variar e se consubstanciar na combinaçáo entre cooperação e conflito. Nesse caso, configura-se, pois, um padrão de cooperação conflitual. A noção de cooperação conflitual é útil aos propósitos deste estudo, pois ilustra a complexidade e multidimensionalidade dos movimentos, conjectura a permanência do conflito nas interaçóes de cooperação com o Estado. Essa perspectiva de conflito, além de permear as narrativas e projetos concorrentes no interior do movimento, converte-se em açóes práticas e repertórios de contestaçáo contra oponentes claramente definidos. De fato, esse é o caso do $\mathrm{CDDH}$, cujo padrão de interação é mais propenso ao conflito e à contestação, ao embate e à denúncia de políticas governamentais em situaçóes de não reconhecimento ou não implementaçáo de demandas defendidas pelo movimento, pois, ao tratar de direitos humanos, as relaçôes conflitivas com o Estado são circunstancialmente acionadas em prol da garantia de políticas de seu interesse, conforme demonstraram as campanhas mobilizatórias contra a impunidade e a corrupção no aparato estatal e no sistema prisional capixaba, nas décadas de 1990 e 2000. A contestação no padrão de interaçáo do CDDH é expressa, ainda, pelo uso de canais e fóruns alternativos aos arranjos participativos, como a ação judicial e o acesso a organizaçóes nacionais e internacionais de direitos humanos, sendo muitas das suas proposiçóes de cunho contestatório e contrário aos interesses do governo. O movimento, assim, articula uma multiplicidade de esferas públicas: ora espaços institucionais, ora não institucionais; ou seja, uma combinação entre política institucionalizada (insider) e não institucionalizada (outsider), nos termos de Goldstone (2003). Esse movimento desenvolveu habilidades em combinar formas criativas de ação e negociaçáo política voltadas ao equilíbrio entre a estabilidade e previsibilidade das interaçóes institucionalizadas e cooperativas, de um lado, e o ambiente instável e incerto produzido por relaçóes contestatórias e de confrontação, de outro, o que resulta em um "padrão de interação híbrido" ou de "cooperação conflitual".

A Acapema, por seu turno, configurou um padrão de interaçáo contestatório, não colaborativo e de limitado engajamento nas agências do Estado, sendo de baixa densidade e diversidade os canais de participaçáo institucional 
em que atuaram e descontínua a durabilidade da sua representação nas esferas participativas. Esse padrão é caracterizado, ainda, pela não integração do movimento a comitês ou a órgáos públicos de implementação de políticas públicas e por sua não adesão a programas e convênios governamentais que delegam a execução de políticas às organizaçóes da sociedade civil. Por fim, o caráter contencioso da sua relação com o Estado é qualificado pelo uso de fóruns alternativos à concretização de suas açóes, a exemplo da ação civil pública no Judiciário, acessados como arenas de vocalização de demandas e proposiçóes conflitivas e contrárias aos interesses de governos. $\mathrm{O}$ padráo de interaçáo conflitual da Acapema, definido pelos ativistas como combatente e denuncista, nutre a permanência do seu posicionamento autônomo e crítico em relação às instituiçóes políticas e o setor privado e se mantém cético quanto às possibilidades de conjugação da autonomia ao modelo cooperativo de relação sociedade-Estado.

A Acapema escapa à tendência de relaçóes de cooperação e parceria com a esfera governamental e o setor privado, comumente desenvolvidas por organizaçôes ambientalistas profissionalizadas. ${ }^{11}$ Casos similares têm sido identificados, como aqueles denominados por Acselrad (2010) de "ecologismo combativo", cujos ativistas buscam preservar a crítica ao modelo de desenvolvimento econômico e se envolver na discussão das políticas públicas de modo crítico e independente. Para os ambientalistas da Acapema, as relaçóes cooperativas e de colaboração pressupóem alianças e sistemas de reciprocidade que são inconciliáveis com a defesa da causa socioambientalista, em que pese o seu discurso de "entidade de contestação do modelo político econômico existente" e de incompatibilidade entre os propósitos do movimento e os interesses governamentais. Justificam, ainda, que o estabelecimento de relaçóes de parceria e cooperação com o governo gera riscos de dependência e submissão do movimento aos interesses governamentais, dado os processos de atrelamento e de cooptação que tornariam a capacidade de crítica e de combate minimizada e a sua autonomia comprometida. No reverso, o estabelecimento de relaçóes de não cooperação e conflito com o governo garantiria ao movimento o posicionamento autônomo, o exercício do questionamento e da crítica na defesa dos interesses coletivos.

II A profissionalização do movimento ambientalista e o seu enfoque técnico e profissional são associados à despolitização e desradicalização da questão ambiental (ROOTES, 2003 apud ALONSO; COSTA; MACIEL, 2007). 
A Figura 1 sumariza os três padróes de interação socioestatal, suas configuraçóes e movimentos correspondentes. Descritivamente: cooperação subordinada ou dependente, caracterizada por cooperaçáa alta, conflito e autonomia baixo (Fams e CPV); cooperação conflitual, qualificada por cooperação, conflito e autonomia alto (CDDH); interaçáo conflitual, caracterizada por cooperação baixa, conflito e autonomia alto (Acapema).

\section{Conflito}

Alto

Baixo

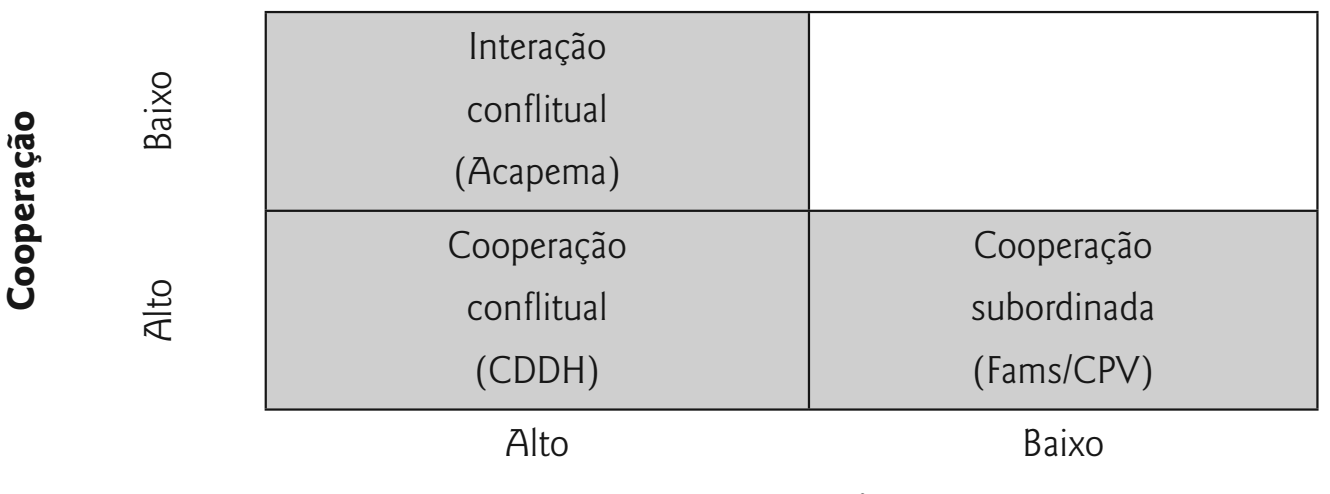

Autonomia

Figura I - Padrões de interação socioestatal no contexto de engajamento institucional: cooperação, conflito e autonomia

Fonte: Pesquisa Movimentos Sociais e Instituições Participativas (2012).

\section{Interações socioestatais cooperativa e conflitual: à guisa de explicação}

No contexto de engajamento institucional os movimentos sociais realçam, predominantemente, padróes de interação cooperativos, ou seja, constituem-se por relaçóes de colaboração e de parceria na elaboração de políticas públicas e na implementação e gestáo de projetos e programas governamentais. Por outro lado, contrariando os enfoques homogeneizantes da açáo coletiva, essas relaçóes se distinguem pelo conflito e pela autonomia. Quais os elementos explicativos das variações nos padrões de interação socioestatal no contexto pós-transição? Sob quais condiçôes se configuram as interações de cooperação e as de conflito com a esfera governamental? Quais os condicionantes da combinação circunstancial entre cooperaçáo e conflito nas relaçóes do movimento com o Estado? Nesta seção, discutem-se duas hipóteses acerca dos padrôes de interaçáo cooperativa e conflitual. 
O nível de engajamento institucional dos movimentos sociais nas IPs e agências governamentais é elencado como principal hipótese explicativa dos padróes de interação socioestatal. Nesse aspecto, há correlação positiva entre a intensidade do engajamento institucional dos movimentos sociais nas IPs e agências estatais e a sua propensão a desenvolver relaçóes cooperativas e colaborativas com a política institucional (CARLOS, 2012, 2015b). Com base nessa hipótese, tem-se a seguinte sentença: quanto maior a intensidade do engajamento institucional do movimento maior a sua propensão a interaçóes cooperativas com a esfera estatal, ao passo que, quanto menor o nível de inserção na política institucionalizada, menos propenso é o movimento de desenvolver relaçóes colaborativas com o Estado. Assim, a Fams, o CPV e o $\mathrm{CDDH}$, organizaçóes de movimentos com alta intensidade de engajamento institucional são mais predispostos a estabelecerem relações cooperativas com o Estado, conquanto se diferenciem quanto ao conflito e a autonomia. Comparativamente, aquele de baixa intensidade (Acapema) é menos inclinado à colaboração com o Estado e mais propenso às interaçóes conflituais.

Essa hipótese coincide com as teses predominantes nas TMS, pelas quais se compreende a cooperação na relação sociedade-Estado como decorrente da institucionalizaçáo do movimento. Esses estudiosos dos movimentos sociais associam o padráo de interaçáo cooperativo às coletividades inseridas na política institucional, e o modelo de ação contestatório e autônomo aos atores societários excluídos e marginalizados do processo político. Porém, essa interpretação dicotômica é inadequada para compreender as mudanças nesses padrôes. Isso porque tende a ofuscar os padrôes de interação plurais e multifacetados caracterizados pela combinação entre cooperação, autonomia e contestação, ignorando a continuidade das relaçóes autônomas e conflitivas no cenário de engajamento institucional. Ao contrário do que presume a literatura, a priori inexiste contradição entre cooperação e autonomia e os padróes de interaçáo cooperativos tanto podem conformar relaçóes subordinadas quanto autônomas. Além disso, a cooperaçáo e a contestação não são, necessariamente, antitéticas e ambas as formas de relação podem ser combinadas aos moldes de um padrão de interação híbrido ou de cooperação conflitual.

A assimilação entre o padrão de interação e o engajamento institucional, embora importante, parece insuficiente para explicar porque alguns movimentos 
cooperam com a esfera governamental e outros a contestam; ou, ainda, quando acionam circunstancialmente a colaboração e o conflito. Evidências deste estudo apontam que o padrão de interação com o Estado não é determinado somente pelo contexto político-institucional, mas é afetado pela gênese relacional do movimento ou pela rede de relaçóes sociais pregressa (CARLOS, 2012, 2015b). Desse modo, a correlação entre padrôes de interação e gênese relacional constitui a segunda hipótese verificada. Especificamente, a significativa presença de vínculos sociais com partidos políticos de esquerda e instituiçôes religiosas na fundação do movimento aumenta a sua propensão a desenvolver interaçôes cooperativas com a esfera estatal, no contexto democrático, conforme comprovou Fams, CPV e CDDH. O contrário é verdadeiro, isto é, o repertório de vínculos pouco afeito a relaçóes com partidos políticos e grupos religiosos na sua fundação reduz a propensão a estabelecer interaçôes colaborativas com agências do governo no cenário pós-transição, exemplificado pela Acapema. A interação de movimentos com instituiçóes do sistema político no contexto de fundação, como o PT e a Igreja Católica, aumenta a sua propensão a interagir com instituiçóes políticas no contexto democrático, porque essas funcionaram como "incubadoras institucionais" para o movimento social contencioso (HOUTZAGER, 2004). Resumidamente, a relação com instituições políticas na fundação do movimento favorece o aprendizado institucional e o reconhecimento dos atores estatais como interlocutores válidos, incentivando-os à colaboraçáo com agências governamentais.

Por fim, uma terceira constatação deste estudo escapa à capacidade explicativa das duas hipóteses examinadas, qual seja, a diferenciação entre as interaçóes cooperativas subordinada e conflitual. Sob quais condições movimentos sociais cooperam subordinadamente ou conflitualmente com o Estado na produção de políticas públicas? De modo complementar às duas principais hipóteses, conjectura-se que a demanda clamada pelo movimento se correlaciona ao padrão de interaçáo socioestatal. Essa explicação confere centralidade ao setor de política pública implicada nas relaçóes do movimento com o Estado e da permeabilidade desse último a dada política (MARQUES, 1996). Baseia-se, também, na ideia de que a colaboraçáo depende do tipo de questão, sendo as interaçóes cooperativas mais prováveis de ocorrer quando a questão ou temática não constitui ameaça para as autoridades políticas (GIUGNI; PASSY, 1998). Isso suposto, as interaçóes cooperativas com a 
esfera estatal, em suas modalidades subordinada ou conflitual, variaria conforme a demanda defendida pelo movimento. Movimentos com reivindicaçóes e propostas negociáveis e permeáveis à agenda governamental tenderiam a interaçôes cooperativas ajustadas aos governos (cooperação subordinada); ao passo que, movimentos que defendem clamores considerados não negociáveis e que constituem ameaças para os governos, são menos propensos a colaboraçáo e tenderiam à contestação e ao conflito (interação conflitual), tendo em vista a incompatibilidade de propósitos e interesses. Por seu turno, movimentos sociais que defendem demandas tanto negociáveis e permeáveis à estrutura do Estado quanto temáticas de trabalho inconciliáveis com interesses do governo ou não porosas à agenda governamental, tenderiam a desenvolver padróes de interação "híbridos" que combinam, circunstancialmente, a cooperação e o conflito (cooperação conflitual). Tratar-se-ia, pois, dos limites da absorção do Estado, cuja permeabilidade estaria condicionada ao setor de política pública. Contudo, o aprofundamento desta hipótese compete a trabalhos futuros.

Em última análise, a compreensão da diversidade nas interaçóes socioestatais requer a consideração das configuraçôes tanto institucionais quanto da sociedade civil, isto é, não somente do contexto de engajamento na política institucional, mas, igualmente, da gênese e conformação dos movimentos. Nesse sentido, são condicionadas pela configuração das instituiçóes, dos atores em intercâmbio e, ainda, das políticas públicas implicadas. A complexidade dos movimentos sociais torna as explicações dicotômicas - cooperação versus conflito e cooperação versus autonomia - limitadas à elucidação da multidimensionalidade na açáo coletiva e exige o reconhecimento do caráter mutuamente constituinte das esferas da sociedade civil e do Estado.

\section{Referências}

ABERS, R.; SERAFIM, L.; TATAGIBA, L. Repertórios de interação Estado-sociedade em um Estado heterogêneo: a experiência da era Lula. Revista Dados, Rio de Janeiro, v. 57, n. 2, p. 325-357, 2014.

.; KECK, M. Practical a authority: agency and institutional change in Brazilian water politics. Oxford University Press, 2013.

; VON BÜLOW, M. Movimentos sociais na teoria e na prática: como estudar o ativismo através da fronteira entre Estado e sociedade? Sociologias, Porto alegre, ano 13, n. 28, p. 52-84, set./dez. 2011. 
ACSELRAD, H. Ambientalização das lutas sociais: o caso do movimento por justiça ambiental. Estudos Avançados, São Paulo, v. 24, n. 68, p. 103-119, 2010.

ALONSO, A.; COSTA, V.; MACIEL, D. Identidade e estratégia na formação do movimento ambientalista brasileiro. Novos Estudos, v. 79, p. 151-167, 2007.

AVRITZER, L. Instituiçóes participativas e desenho institucional: algumas consideraçóes sobre a variação da participação no Brasil democrático. Opinião Pública, Campinas, v. 14, n. 1, p. 43-64, jun. 2008.

CARLOS, E. Movimentos sociais: revisitando participação e institucionalização. Lua Nova Revista de Cultura e Política, São Paulo, v. 48, p. 118-130, 2011.

Movimentos sociais e instituiçóes participativas: efeitos organizacionais, relacionais e discursivos. São Paulo. 2012. 398f. Tese (Doutorado em Ciência Política) - Programa de Pós-Graduação Ciência Política, Universidade de São Paulo, São Paulo, 2012.

- Mudanças e continuidades no movimento de direitos humanos: padróes organizacionais, relacionais e discursivos. Opiniáo Pública, Campinas, v. 20, n. 3, p. 450479, $2014 a$.

Engajamento institucional, mudanças e continuidades na ação coletiva: o movimento popular e o ambientalista no Espírito Santo. In: .; OLIVEIRA, O. P.; ROMAO, W. M. (Org.). Sociedade civil e políticas públicas: atores e instituiçóes no Brasil contemporâneo. Chapecó: Argos, 2014b. p. 29-82.

Movimentos sociais e instituiçóes participativas: efeitos do engajamento institucional nos padróes de ação coletiva. Revista Brasileira de Ciências Sociais, Sáo Paulo, v. 30, n. 88, p. 83-99, jun. 2015a.

Movimentos sociais e instituiçóes participativas: efeitos do engajamento institucional no contexto pós-transição. Belo Horizonte: Fino Traço, 2015 b.

Movimentos sociais e sistema político nas teorias dos movimentos sociais. Interseçóes, Rio de Janeiro, v. 17, n. 1, p. 54-78, jun. 2015c.

DIANI, M. Introduction: social movements, contentious actions, and social networks: 'from metaphor to substance'? In: .; MCADAM, D. (Org.). Social movements and networks: relational approaches to collective action, Oxford: Oxford University Press, 2003. p. 1-18.

; BISON, I. Organizações, coalizões e movimentos. Revista Brasileira de Ciência Política, v. 3, p. 219-250, 2010. 
DOIMO, A. A vez e a voz do popular: movimentos sociais e participação política no Brasil pós-70. Rio de Janeiro: Relume-Dumaré/Anpocs, 1995.

DOOWON, S. Civil society in political democratization: social movement impacts and institutional politics. Development and Society, v. 35, n. 2, p. 173-195, dez. 2006.

DOWBOR, M. A arte da institucionalização: estratégias de mobilização dos sanitaristas (1974-2006). 2012. 295f. Tese (Doutorado em Ciência Política) - Programa de Pós-Graduação Ciência Política, Universidade de São Paulo, São Paulo, 2012.

GEORGE, A. L.; BENNETT, A. Case studies and theory development in the social sciences. Cambridge, MA: The MIT Press, 2004.

GIUGNI, M. G.; PASSY, F. Contentious politics in complex societies: new social movements between conflict and cooperation. In: .; MCADAM, D., TILLY, C. (Ed.). From contention to democracy. Rowman and Littlefield Publishers, 1998. p. 81-107.

GOLDSTONE, J. Bridging institucionalized and noninstitucionalized politics. In:

(Ed.). States, parties, and social movements. Cambridge: Cambridge University Press, 2003.

GURZA LAVALLE, A.; HOUTZAGER, P.; CASTELLO, G. La construcción política de las sociedades civiles. In: GURZA LAVALE, A. (Org.). El horizonte de la política. Brasil y la agenda contemporánea de investigación en el debate internacional. México: CIESAS, 2011. p. 207-267.

Após a participação: nota introdutória. Lua Nova, São Paulo, v. 48, p. 13-23, 2011.

; SZWAKO, J. Sociedade civil, Estado e autonomia: argumentos, contra-argumentos e avanços no debate. Opiniáo Pública, Campinas, v. 21, n. 1, p. 157-187, abr. 2015.

HANAGAN, M. Social movements, incorporation, disengagement, and opportunities - a long view. In: GIUGNI, M. G.; MCADAM, D., TILLY, C. (Ed.). From contention to democracy. Rowman and Littlefield Publishers, 1998. p. 3-29.

HOUTZAGER, P. Os últimos cidadáos. Conflito e Modernização no Brasil Rural. São Paulo: Globo, 2004.

ISUNZA VERA, E. Interfaces socioestatais, prestação de contas e projetos políticos no contexto da transição política mexicana (dois casos para reflexão). In: DAGNINO, E.; OLVERA, A. J.; PANFICHI, A. (Org.). A disputa pela construçáo democrática na América Latina. São Paulo: Paz e Terra; Campinas: Unicamp, 2006. p. 261-307.

.; GURZA LAVALLE, A. Arquitetura da participação e controles democráticos no Brasil e no México. Novos Estudos, São Paulo, v. 92, p. 105-121, mar. 2012. 
JENKINS, J. C. Social movements, political representation and the state: an agenda and comparative framework. In: .; KLANDERMANS, B. (Ed.). The politics of social protest: comparative perspectives on states and social movements. Minneapolis: University of Minnesota Press, 1995. p. 14-38.

KRIESI, H. P. La estructura organizacional de los nuevos movimientos sociales en su contexto político. In: MCADAM, D.; McCARTHY, J.; ZALD, M. (Ed.). Movimientos sociales: perspectivas comparadas. Madrid: Istmo, 1999. p. 221-261.

MCADAM, D; TARROW, S.; TILLY, C. Dynamics of contention. Cambridge studies in contentious politics. Cambridge: Cambridge University Press, 2001.

McCARTHY, J.; ZALD, M. The trends of social movements in America: professionalization and resource mobilization. Morristown, N. J.: General Learning Press, 1973.

MISCHE, A. Cross-talk in movements: reconsceiving the culture-network link. In: DIANI, M.; MCADAM, D. (Org.). Social movements and networks. Relational approaches to collective action. Oxford University Press, 2003. p. 258-280.

MELUCCI, A. Challenging codes. Cambridge/New York: Cambridge University Press, 1996.

MEYER, D.; TARROW, S. (Org.). The social movement society: contentions politics for a new century. Lanham, MA: Rowman \& Littlefield, 1998.

PAOLI, M. C. Movimentos sociais no Brasil: em busca de um estatuto político. In: HELLMANN, M. (Org.). Movimentos sociais e democracia no Brasil. "Sem a gente não tem jeito". São Paulo, Marco Zero/Ildesfes/Labor, 1995. p.24-55.

PENNA, C. A relação de parceria entre o INCRA e os movimentos sociais no processo de implementação das políticas de reforma agrária. Interseçóes, Rio de Janeiro, v. 17, n. 1, p. 188-224, jun. 2015.

PETERS, B. G. Comparative politics: theory and methods. New York: New York University Press, 1998.

PIRES, R. R.; VAZ, A. Participação faz diferença? Uma avaliação das características e feitos da institucionalização da participação nos municípios brasileiros. In: AVRITZER, L. (Org.). A dinâmica da participação local no Brasil. São Paulo: Cortez, 2010. p. 253-304. .; Para além da participação: interfaces socioestatais no governo federal. Lua Nova, São Paulo, n. 93, p. 61-91, 2014. 
PIVEN, F. F.; CLOWARD, R. Poor people's movements: why they succeed and how they fail. New York: Vintage Books, 1979.

REIS, E. (Org.) Novos vínculos entre a sociedade e o Estado. Rio de Janeiro: 7 Letras, 2013.

SADER, E. Quando novos personagens entram em cena. Experiências, falas e lutas dos trabalhadores da Grande São Paulo (1970-80). São Paulo: Paz e Terra, 1988.

SILVA, M. K. De volta aos movimentos sociais? Reflexóes a partir da literatura brasileira recente. Ciências Sociais Unisinos, São Leopoldo, v. 46, n. 1, p-2-9, jan./abr. 2010.

; OLIVEIRA, G. L. A face oculta(da) dos movimentos sociais: trânsito institucional e intersecção Estado-Movimento - uma análise do movimento de Economia Solidária no Rio Grande do Sul. Sociologias, Porto Alegre, ano 13, n. 28, p. 86-124, set./dez. 2011.

SKOCPOL, T. Protecting soldiers and mothers: the political origins of social policy in the United States. Cambridge: Belknap Press/Harvard University Press, 1992.

SZWAKO, J. E. L. "Del otro lado de la vereda”: luta feminista e construção democrática no Paraguai pós-ditatorial. 2012. 440f. Tese (Doutorado em Ciências Sociais) - Programa de Pós-Graduação Ciências Sociais, Universidade de Campinas, Campinas, 2012.

TARROW, S. El poder en movimiento: los movimientos sociales, la acción colectiva y la política. Madri: Alianza, 1997.

TATAGIBA, L. Desafios da relação entre movimentos sociais e instituiçóes políticas. O caso do movimento de moradia da cidade de São Paulo - Primeiras reflexóes. Colombia Internacional, v. 71, p. 63-83, 2010.

TATAGIBA, L.; TEIXEIRA, A. C. Efeitos combinados dos movimentos de moradia sobre os programas habitacionais autogestionários. Sociologia Política. v. 24, n. 58, p. 85-102, jun. 2016.

TILLY, C. Social movements, 1768-2004. Boulder/London: Paradigma, 2004.

TOURAINE, A. An introduction to the study of social movements. Social Research, v. 52, p. 749-788, 1985. 


\section{Cooperation and Conflict in the Relationship of Social Movements and State}

\section{Abstract}

The article analyzes the reconfiguration of the relationship between social movements and state in the Brazilian context post 1990, and its institutional effects on collective action. The socioestatais interactions are examined by the comparative method applied to four social movements organizations in state of Espírito Santo along three decades (1980-2010), through qualitative and quantitative methods: Federation of Neighborhood Associations of Serra (Fams), Popular Council of Vitória (CPV), Center for the Defense of Human Rights of Serra (CDDH) and Association of Environmental Protection (Acapema). Contrary to dichotomous views of the relationship between civil society and the state, the study identifies a heterogeneity of interrelationships in terms of cooperation, conflict and autonomy. The analysis establishes correlations between socioestatal interaction patterns and the institutional effects, be it of the engagement in participatory institutions or of the connections with institutions in the genesis of the movement.

Keywords: Social movements. Participatory institutions. Institutionalization. Socioestatais interactions.

Recebido em: 09/03/2016

Aceito em: 24/11/16 